\title{
Dirigiéndose al sur pero mirando al norte: globalización y reforma del Derecho en América latina*
}

Joseph R. Thome

En toda Latinoamérica la reforma del Derecho está en el aire. Después de décadas de negligencia, sus sistemas legales están experimentando procesos sustanciales sino drásticos de reforma y transformación. La administración de justicia en particular ha sido distinguida como ineficiente, sino corrupta, inaccesible para la mayoría, incapaz o sin disposición para responder a los abusos de derechos humanos, y mayormente irrelevante para las necesidades de las economías modernas.

Estos procesos de reforma responden a actores y presiones nacionales y mundiales. En la superficie, ambos comparten la meta de ayudar a consolidar un buen ejercicio del gobierno, incluyendo el régimen de derecho, en toda Latinoamérica. No obstante, este consenso objetivo puede desglosarse en dos orientaciones diferentes que revelan no sólo acuerdos sino también sobreposición y algunas veces objetivos en conflicto:

a) Orientación del mercado: un medio legal apropiado que incluya reglas uniformes, predecibles y ejecutables que garanticen la propiedad y los derechos contractuales se considera como crucial para modernizar las economías latinoamericanas y para incorporarlas en la economía global caracterizada por comercio irrestricto y rendimiento del mercado libre;

* Ponencia presentada en la Junta Anual de Derecho y Sociedad 2000. Miami Beach, Florida, del 26-29 de mayo del 2000. Una versión de esta ponencia se publicará en otoño del 2000 en la Revista de Derecho de la Universidad de Wisconsin. 
b) Orientación democrática: un imperio de ley efectivo se considera también como vital para consolidar las instituciones democráticas; haciendo que los sistemas legales sean más transparentes, sensibles a las necesidades sociales y accesibles a los sectores de la sociedad desfavorecidos; y para evitar las violaciones de los derechos humanos al mismo tiempo que para hacerse más efectivos en la prevención y la sanción de la actividad criminal.

Además, tanto los actores nacionales como mundiales también parecen acordar que alcanzar estas metas algo contradictorias requerirá una administración de justicia más independiente, efectiva y accesible, que incluya amplios poderes de revisión judicial y nuevas instituciones para juicios y procesos civiles y penales en todo el complejo conjunto de instituciones que constituyen la administración del sector de justicia. En realidad, en años recientes varias naciones de Latinoamérica han incluido propuestas de reformas en los marcos legales nacionales a través de modificaciones constitucionales o nueva legislación.

Pero esta aparente armonía de intereses, metas y medios puede enmascarar cierta vaguedad conceptual así como tensiones y contradicciones entre las metas y políticas nacionales y globales, y, en realidad, incluso entre éstas. Establecer marcos legales amistosos con el mercado puede chocar con el objetivo democrático de facilitar el acceso a las cortes a intereses históricamente excluidos, tales como trabajadores no sindicalizados, mujeres y los pobres en general. De manera similar, una mayoría de la población que enfrenta una creciente criminalidad puede usar medios democráticos para ejercer presión para lograr un cumplimiento de la ley más eficiente y más estricto incluso a costa de los derechos humanos de aquellos sospechosos de actividad criminal. Finalmente, las distorsiones potenciales de los programas o implementación de problemas también se pasan por alto algunas veces. Correa (1993:97), por ejemplo, ha señalado que los elementos dominantes del poder judicial pueden apoyar aparentemente la reforma legal pero, percibiéndolos como amenazantes para sus intereses corporativos o estatus dentro de la administración de justicia, pueden operar entre bastidores para minar o controlar el proceso.

Este tapiz socio-legal difícil de desenmarañar exige estudios profundos de objetivos de reforma, de contextos sociales, políticos y nacionales y globales en los cuales se insertan los procesos de reforma, y de los 
diversos conflictos, tensiones y algunas veces consecuencias imprevistas que estas reformas ocultan o han producido. Afortunadamente, estos estudios están comenzando a surgir, a pesar que aún es difícil conseguir estudios empíricos y evaluadores. Si bien este trabajo no pretende ser el producto de estudios de campo y empíricos, tratará de sacar a la luz algunos de los valores y las premisas que subyacen en las políticas de reforma tanto nacionales como globales, y de examinar otros factores algunas veces no formulados pero no obstante relevantes que afectan tanto la articulación como la implementación de objetivos de reforma, incluyendo los vínculos entre los actores nacionales y globales y las fuerzas sobre estos procesos de reforma legal.

\section{La perspectiva global de la reforma legal en Latinoamérica}

Debido a los vínculos percibidos entre el régimen de derecho, democracia y desarrollo, la reforma legal ha devenido un punto focal en el mundo de la ayuda internacional. El mundo, claro está, ha cambiado; el fin de la Guerra Fría y el colapso de la Unión Soviética, así como la aparición de la hegemonía occidental, sin duda alguna, desempeñó un papel clave en el surgimiento de este énfasis en las instituciones democráticas y en el desarrollo orientado al mercado. Por un lado, los derechos humanos internacionales se han convertido en parte de agendas políticas nacionales, dirigiéndose a la necesidad de reforma legal para cumplir sus principios. Por otro lado, el "Consenso Washington" ha devenido en "[...] el paradigma dominante en el pensamiento del desarrollo [...]". Como tal, éste "[...] promueve mercados como instituciones de distribución, favorece la privatización y promueve vínculos más cercanos con la economía global». Lograr esta meta exige un marco legal apropiado, hacer que la reforma legal sea esencial (Trubek, 1996:224-225).

En gran medida este proceso global ha brindado la oportunidad de centrarse en las fallas económicas, la corrupción, los abusos de derechos humanos y males similares que plagan la mayor parte de las naciones en desarrollo, en gran medida debido a que prevalecen regímenes patrimoniales e instituciones no democráticas. Como dice Donelly (1999:610): «la democracia, a pesar de que no es estrictamente necesaria para el desarrollo [...] puede limitar el desgobierno de rapińa que 
mina el desarrollo». La negación sistemática de los derechos políticos y civiles no necesariamente dificulta el desarrollo económico, tal y como lo muestra la experiencia de Europa y de los Estados Unidos en el siglo XIX, y Corea del Sur, Taiwán, Brasil y Chile en décadas recientes, cuestionando la relevancia de un medio legal democrático para el desarrollo de economías de mercado libre. No obstante, si bien el poder de los derechos humanos y de conceptos tales como democracia y régimen de derecho no debe sobre enfatizarse, la declaración de Viena de 1993 constituye un fuerte endoso de la universalidad de dichos derechos y la mayoría de los estados hoy en día apelan a los derechos humanos, democracia y desarrollo como una forma de establecer la legitimidad nacional e internacional. Más aun, «[...] los derechos civiles y políticos, al proporcionar rendición de cuentas y transparencia, pueden ayudar a canalizar crecimiento económico hacia el desarrollo nacional más que el enriquecimiento privado" (Donelly, 1999: 610-611). Esta posición a su vez ha llevado a una necesidad percibida por un orden constitucional liberal con pluralismo político, elecciones justas, un poder judicial fuerte e independiente y una administración eficiente y responsable. El constitucionalismo, ha sido "acogido" (Ghai, 1993: 52-53).

El constitucionalismo liberal es en realidad relevante para Latinoamérica, particularmente en vista de las transiciones actuales de regímenes autoritarios a democráticos y de economías intervenidas por el estado a mercados libres e inserción en economías globales. Los componentes de esta transición incluyen la separación del estado y la sociedad civil, el régimen de derecho, y la limitación del alcance del poder gubernamental. El constitucionalismo liberal y el régimen de derecho incluyen ciertos valores básicos que enfatizan los derechos de propiedad, políticos y civiles individuales, apuntalados por el concepto de igualdad de todos los ciudadanos de conformidad con la ley. Esta es una ideología poderosa que puede ser, y algunos argumentarán, ha sido, utilizada para legitimizar el dominio de elites y regímenes occidentales en todo el mundo, limitando al mismo tiempo el poder arbitrario del Estado (Ghai, 1993:53-56).

De esta manera, el debate acerca de la reforma legal nos lleva al rol del Estado y el derecho en el actual proceso de globalización. El Estado ahora debe luchar con diferentes fuerzas; nacionalidades, debe tratar con todas las demandas y constricciones del proceso político interno, e internacionalidad, debe responder a procesos y presiones políticos y 
económicos globales. Este escenario introduce complejidades a las nociones clásicas del Estado y necesariamente tiene impacto en las esferas legales afectadas.

En Latinoamérica, el concepto recibido de ciencia legal está profundamente arraigado como un principio de fundación de los nuevos sistemas legales dentro de décadas de su independencia a comienzos del siglo XIX. Como corresponde a una "ciencia", el derecho se percibió como racional y no político. Respondiendo a impulsos similares para moldear estaciones nacionales partiendo de diversas facciones $y$ etnicidades, las naciones latinoamericanas nacientes también recibieron el concepto de "positivismo legal» de Europa; el Estado debía ser la única fuente de derecho y a todas las otras normas se les daba un estatus de subsidiaria como social, religiosa, o, en el caso de la gente indígena, normas primitivas. No obstante, el estatismo legal oficial nunca estableció por completo un monopolio verdadero sobre las relaciones legales. Adicionalmente al derecho nacional, tanto el derecho local como el supra-nacional siguió jugando un papel importante en la regulación del comportamiento individual, social y del estado. En realidad, estas pluralidades legales se han vuelto más prominentes y reconocidas en el actual proceso de globalización.

Los países de Latinoamérica también abarcaron la doctrina francesa original de separación de poderes según la cual las cortes debían jugar un rol relativamente menor en el proceso legal: no debía hacer la ley, sólo interpretarla y aplicarla. Según esta doctrina, no existen precedentes vinculantes, ni revisión judicial erga omnes de la constitucionalidad de las leyes, como se contrasta con la constitucionalidad de su aplicación a un caso específico, individual. Si bien las cortes por lo general pueden revisar la legalidad de las acciones administrativas, esta revisión por lo general se limita a la aplicación específica y particular del poder ejecutivo, y no tiene una aplicación amplia con la ley o reglamento en consideración. Los países de Derecho civil se han estado moviendo hacia un tipo norteamericano de revisión judicial, pero éste es un desarrollo reciente y no se ha convertido aún en la norma en toda Latinoamérica.

Huelga decir que el final de milenio trajo consigo nuevos retos a paradigmas de modernidad reflejados en dichas nociones del Estado y el derecho. Para Santos los sistemas legales son híbridos, ya que reflejan múltiples modernidades y tradiciones. Por ejemplo en Latinoamérica, 
lo pre-moderno, lo moderno y lo post-moderno coexisten incluso entre la misma gente. A pesar de que Latinoamérica siempre estuvo activa en los mercados mundiales, la reciente y completa integración en las economías globales dominadas por el norte hace que la "hibridización" legal sea incluso más evidente. Según Santos, podríamos decir que el proceso de globalización consta de dos modos principales:

"Localismo globalizado», describe el proceso mediante el cual una condición local logra ampliar su alcance en todo el mundo, con la capacidad de designar cualquier otra condición como «local». Los ejemplos pueden ir desde proliferación de los distribuidores de comida rápida hasta las estrategias de administración de compañías del primer mundo. En realidad, algunos argumentarían que los actuales programas de reforma legal en gran medida reflejan este proceso, ya que las instituciones legales europeas o norteamericanas devienen en la base de dichas reformas.

"Globalismo localizado", por otro lado, hace referencia al impacto de la institución recibida sobre el contexto local, e inversamente, cómo este contexto local, tales como una cultura política y legal diferente, a su vez afecta la institución o proceso recibidos. Una reforma legal con componentes importados bastante similares produce resultados en, digamos, Costa Rica que son diferentes a los que produce en el Perú. En cualquier cosa, las instituciones resultantes no coincidirán con aquéllas de la nación "exportadora».

La relación dinámica entre estos dos modos afecta en forma sustancial la forma y el contenido de los programas de reforma legal actuales. Esta es una "zona de frontera", cargada de ambigüedades, en donde contextos y realidades diferentes producirán resultados diferentes (Sassen 1999). Tal y como se examina detalladamente más adelante, por ejemplo, los programas y las políticas de reformas del derecho del Banco Mundial se han vuelto más sensibles socialmente hablando, cambiando de una orientación de mercado restringido a un lente más amplio que incluye al indígena, el pobre, y otros sectores marginales de la sociedad. Desde mi punto de vista, esta evolución probablemente refleja un efecto "localizador"; a medida que las políticas y los programas del Banco elaborados en Washington se dirigen al sur, se oyeron nuevas y a menudo conflictivas voces y el Banco comenzó a reajustar su agenda. No obstante, al Banco le falta resolver contradicciones inherentes o conflictos dentro de su nueva agenda más amplia. 


\subsection{El Banco Mundial: políticas de reforma del Derecho y estrategias de implementación}

La reforma legal, en particular en lo que se refiere al rol del poder judicial en el desarrollo económico y social, ha devenido en un ingrediente esencial entre las políticas y programas de las agencias multilaterales. El Banco Mundial es un jugador importante en la promoción de la reforma legal. Según el asesor general del Departamento Legal del Banco Mundial, por ejemplo, las actividades del Banco Mundial para reforzar las instituciones y las políticas que afectan los sistemas legales y judiciales han crecido marcadamente en los últimos años. El Banco ha preparado diez operaciones de reforma judicial autónomas que han sido aprobadas por el Directorio, y otras catorce están en proceso de preparación. Además, otros quince proyectos tratan temas legales y judiciales desde una perspectiva sistemática amplia, tales como reformas del proceso de elaboración de leyes y el poder judicial y mecanismos alternativos para la resolución de disputas. Además de esto, hay unas trescientas cincuenta operaciones en ochentisiete países que financian actividades específicas de reforma legal (Rigo Sureda, 1999:20).

Inicialmente, el centro de atención del Banco parecía estar estrechamente fijado en «repensar el rol del Estado y el modo actual de desarrollo $[. .$.$] », con la finalidad de colocar «[...] una mayor confianza en$ los mercados y el sector privado, con el Estado actuando como un facilitador importante y regulador de la actividad y desarrollo de la actividad del sector privado". Alcanzar este objetivo requeriría un importante esfuerzo de reforma que incluya «[...] la elaboración de un marco legal para el desarrollo, y cumplimiento del régimen de derecho». (Aiyer, en Rowat et. al. 1995:vii). El poder judicial, en su calidad de componente esencial de este proceso tendría que fomentar un medio judicial y legal habilitante que lleve al comercio, financiamiento y la inversión. No obstante, según la opinión del Banco el poder judicial de Latinoamérica se ha convertido en un impedimento para estas metas ambiciosas debido a su ineficiencia, tal y como se caracteriza por las largas demoras en los casos, el limitado acceso a la justicia, la falta de transparencia y predictibilidad, y la pobre confianza del público en el sistema. Así, el objetivo del desarrollo económico sostenible se percibió en riesgo debido a la falta de ejecución del régimen de derecho. Dakolias 
(1995: 167-169), un funcionario del Banco que está muy involucrado en sus esfuerzos de reforma del derecho, también considera la reforma judicial como un componente clave para promover el desarrollo económico, puesto que los sistemas judiciales autónomos y confiables constituyen una condición básica para ser miembro de la economía global, acarreando la responsabilidad de traer consigo la armonización del derecho y asegurando a los comerciantes exteriores y los inversionistas que la ley se aplicará de acuerdo con las normas regionales e internacionales.

A medida que el Banco está más consciente de la complejidad del "sector judicial», su rol en la sociedad, y de los problemas que implica tratar de lograr reformas en sociedades con intereses, grupos e instituciones en conflicto, la articulación del Banco de las políticas y las estrategias para la reforma legal han devenido más matizadas y contextualizadas. Por ejemplo, desde 1995 reconoció que implementar reformas requeriría un proceso gradual o un aumento factible dentro de la capacidad política y económica de cada nación. Dadas las limitaciones políticas y las consideraciones pragmáticas, el Banco encontró que la construcción de coalición era necesaria. Además, el Banco aparentemente sabía que el empujón inicial para el proceso de reforma debía venir desde dentro del país afectado; habiéndose sugerido como mecanismos para elevar la base amplia necesaria de apoyo la participación a nivel popular, reuniones en las ciudades y otras participaciones locales. (Dakolias, 1995: 225-231).

No obstante, un estudio de 1996 realizado por el Comité de Abogados de Derechos Humanos (Comité de Abogados) y el Programa Venezolano para la Educación de Derechos Humanos (PROVEA) del Proyecto de Infraestructura Judicial de Venezuela financiado por el Banco Mundial documentó amplias brechas entre las políticas articuladas del Banco y sus acciones. Lanzado en 1992, este proyecto de reforma judicial se vio apoyada por un préstamo del Banco por $\$ 30$ millones y su asistencia técnica; en realidad, se "[...] "comercializó" como el compromiso insignia del Banco en esta área, preparando el escenario para una serie de otros proyectos de reforma judicial en Latinoamérica y en otros lugares" (Comité de Abogados, 1996:1).

El Informe cita el reconocimiento del Banco de que la reforma no podría imponerse desde fuera. Además, el Banco también enfatizó la necesidad de estudios de diagnóstico previos y estableció diversos cri- 
terios esenciales para la implementación del programa. Pero a partir de 1996, "[...] el registro del Banco a la fecha en cada una de estas áreas, desafortunadamente, se ha mezclado en el mejor de los casos" (Comité de Abogados, 1996: 3). El proyecto no era parte de una amplia estrategia de reforma; no había amplio comité de gobierno que reformar; las estrategias de reforma no trataban los impedimentos estructurales cruciales para la independencia judicial; no se trataba el acceso a los asuntos de justicia; y, no había una participación de ancha base en el diseño y desarrollo del proyecto. En consecuencia, los logros reales se veían limitados en su alcance (Comité de Abogados, 1996: 6-10).

En realidad, las articulaciones de política del Banco ahora reflejan una comprensión más amplia de las diversas metas, principios e intereses que se ven afectados por los programas de reforma del derecho. Por ejemplo, el Banco ha vinculado el desarrollo con la protección de los derechos humanos, lo que a su vez depende de un poder judicial fuerte, accesible e independiente. Al mismo tiempo, el Banco ha declarado que «las cortes accesibles y eficientes son esenciales para lograr un crecimiento económico sostenible y de ancha base. En cualquier sociedad que busca lograr crecimiento económico, el gobierno debe garantizar que los contratos sean cumplidos y que se respeten los derechos de propiedad, y que los inversionistas nacionales y extranjeros confien en éste para asegurar que sus inversiones gocen de protección legal, con acceso" (Press Backgrounders, 1999). El Banco también ha manifestado que los derechos humanos en los países en desarrollo se salvaguardan mejor al mejorar las condiciones de las comunidades indígenas. Los programas orientados a lograr este objetivo incluyen la mejora en la calidad de la educación, salud y sanidad, reforma de la tierra y reforma judicial.

James D. Wolfensohn, el presidente del Banco Mundial, sabe bien que las economías de mercado recompensan a unos más que a otros. Al hacer referencia a los países en desarrollo, él reconoce que las poblaciones "permanecen divididas a lo largo de una línea de falla que separa las vidas y las aspiraciones de los ricos y de los pobres» (N.Y. Times, 2000: 10). Además, él considera los sistemas legales como cruciales, en el sentido que sin la protección de los derechos humanos y de propiedad y un marco de leyes completo, no es posible lograr un desarrollo equitativo. Un gobierno debe garantizar que tiene sistemas efectivos de propiedad, contractuales, laborales, de insolvencia, códigos comerciales, leyes de derechos personales, y otros elementos de un sistema legal 
cabal que sea administrado en forma efectiva, imparcial y limpia mediante un sistema legal y judicial que funcione bien, imparcial y honesto (Citado por Rigo Sureda, 1999: 19).

Incluso, la articulación de la política del Banco y el énfasis del programa refleja metas contradictorias, aparentemente no reconocidas por el Banco, y sus posiciones aparentemente continúan para reflejar en gran medida una orientación "localismo globalizado".

Esto no es para decir que las posiciones de estrategia y política del Banco son irracionales e indefendibles. Pero las contradicciones inherentes en las políticas y los programas del Banco plantean importantes interrogantes que pueden afectar en forma vital la implementación de sus programas. Se debe reconocer y tratar la diversidad de intereses e incluso conflictos entre los diferentes sectores de la sociedad. Un ejemplo importante es el problema de la criminalidad en aumento y la demanda social por políticas más efectivas, lo que claramente engendra tensión entre las demandas por «ley y orden» y los derechos humanos internacionalmente reconocidos de debido proceso y trato humano de aquellos acusados de actividad criminal. En forma similar, los campesinos sin tierras de Guatemala interpretarán el llamado del Banco para una reforma de la tierra en una forma que inevitablemente chocarán con la interpretación del terrateniente de la posición fuertemente sostenida del Banco Mundial de que los derechos contractuales y de propiedad son esenciales para el desarrollo. Los conflictos entre los indígenas sosteniendo sus derechos ancestrales a la tierra y los intereses de los inversionistas locales o extranjeros, contrato del gobierno, se han convertido en tópicos comunes, algunas veces llevando a abandonar los proyectos. Si a la larga se requiere un tipo de intervención judicial u otra intervención "oficial", ¿cómo se resolverían estos conflictos? ¿A través de leyes indígenas "comunes» e instituciones, o de conformidad con los sistemas legales nacionales «eficientes» y reformados que el Banco ha estado promoviendo?.

Para estar seguro, tal y como se ha mencionado, el Banco parece haber aprendido a partir de su experiencia y ha ampliado su política y agenda de programas. Sin embargo, el poder judicial sigue siendo la piedra angular de los programas de reforma legal del Banco. ¿Pero un énfasis tal ha sido bien colocado? Incluso una visión superficial de la historia legal de Latinoamérica revela un poder judicial con poca relevancia social, por lo general subordinado al poder ejecutivo en la ma- 
yoría de temas políticos importantes en la medida que sus prerrogativas corporativas sean preservadas, y mayormente comprometido en actividad rutinaria. En realidad, la imagen del juez sigue siendo aquella de un burócrata sin rostro adverso a la innovación. A pesar de algunas excepciones importantes tales como Costa Rica y algunos jueces claramente dedicados e innovadores, la mayoría de los poderes judiciales latinoamericanos no han mostrado aún un compromiso verdadero con la panoplia total de instituciones y derechos democráticos.

En realidad, podríamos ver con escepticismo la relevancia de adoptar procesos judiciales costosos y «modernos» en por lo menos aquellos países en donde el "régimen de derecho" rara vez ha sido legítimo y mucha gente ni siquiera sabe leer. Los poderes de revisión judicial e independencia para una Corte Suprema de una nación junto con los sofisticados sistemas computarizados, por ejemplo, pueden ser irrelevantes para la mayoría de gente, cuya interacción con la «ley» por lo general está limitada a burócratas de bajo nivel y la policía. En este contexto, ¿una mejor administración oficial de justicia necesariamente llevará a un poder judicial más accesible para todos, o simplemente a un mecanismo más eficiente para proteger los intereses de los sectores de la sociedad aventajados?.

Nada de lo antedicho es para negar que el poder judicial y los procesos legales en Latinoamérica no necesitan mejoras sustanciales. Sus insuficiencias y problemas han sido bien documentadas. Pero existen riesgos claros en el uso de modelos que vienen del norte para fijar las «insuficiencias» legales sin considerar debidamente las necesidades particulares y los contextos de las sociedades «receptoras» del sur.

\section{La perspectiva nacional, o localización de lo global}

Las políticas y programas globales, incluso si se han acordado, a menudo están mediadas y se les da nuevos significados o incluso se ven desviados por la realidad nacional. Además, la relación dinámica entre las fuerzas locales y globales también afecta la agencia exportadora, que puede comenzar a cuestionar algunas de sus premisas iniciales, políticas y estrategias operacionales. Un caso es la evolución de las posiciones del Banco Mundial en relación con los programas de reforma del derecho que ha promovido en Latinoamérica. 
De esta manera, la comprensión del contexto local es necesaria para cambiar de una perspectiva etnocéntrica "globalizadora" a una «localizadora»; este ejercicio proporcionará interrogantes y temas diferentes -si no algunas veces que se sobrepongan- que están más arraigados en el contexto social en particular. En toda Latinoamérica, por ejemplo, los principios y proceso de "régimen de derecho" son proclamados en documentos oficiales y reiterados en normas legales sustantivas. Pero en la práctica a menudo están ausentes o desigualmente distribuidos, produciendo una brecha entre el «derecho en libros» ideal y el «derecho en acción» operativo, incluso dentro de las sociedades más desarrolladas de Latinoamérica. Esta situación depreda los regímenes autoritarios de la década de los años 70 y 80 y, desafortunadamente, continúa en cierta medida para plagar tanto las sociedades re-democratizadas (por ejemplo, Argentina, Brasil, Chile, y El Salvador) y otras que discutiblemente no sufrieron de los regímenes autoritarios (por ejemplo, Colombia, México y Venezuela). En realidad, de acuerdo con Pinheiro, «desde el retorno de la ley democrática a muchos países en Latinoamérica, las relaciones entre los gobiernos y los miembros de la sociedad se han visto caracterizadas por un uso ilegal y arbitrario del poder», con muchas prácticas autoritarias y violaciones de derechos humanos que no se han visto afectadas por los cambios políticos o elecciones (1999:1).

Esta situación se debe mayormente al contexto socio-político, el cual tiene un impacto directo sobre las normas, procesos, estructuras institucionales y cultura de un sistema legal dado. En la mayor parte de Latinoamérica, por ejemplo, los sistemas judiciales tradicionalmente fueron politizados, por lo general entrelazados o dependiendo del poder ejecutivo, incluso en la medida que retenían sustancial autonomía corporativa. Este rasgo patrimonial, parte de la herencia colonial de la región, se hizo incluso más evidente en la década de los años 20 y los años 30 cuando en respuesta a la presión proveniente de abajo y la crisis económica de los tiempos, las sociedades de Latinoamérica emprendieron programas de desarrollo de sustitución de importación nacionalistas llevados a cabo por un Estado regulador intervencionista y benefactor dominado por el Poder Ejecutivo. Debido a que el sector público debía prevalecer sobre las fuerzas del mercado, el Poder Ejecutivo asumió un papel clave en la resolución de conflictos entre diversos sectores económicos clave y empresas, en donde las consideraciones 
ideológicas y políticas a menudo se consideraron más importantes que la eficiencia económica o las prescripciones legales. En el proceso, el papel del poder judicial devino relativamente mínimo, ya que los conflictos importantes fueron aireados y resueltos en otras arenas -agencias administrativas, empresas estatales semiautónomas o las oficinas de un Ministro o del Presidente mismo (Correa, 1993: 94; Perez Perdomo, 1993: 132-135). Los tribunales fueron relegados a funciones tales como decidir los casos de cobro de deudas, o al procesamiento de criminales comunes (los crímenes de cuello blanco fueron ampliamente ignorados).

Este proceso tenía consecuencias muy negativas para una Administración de Justicia que ya era débil. Los jueces llegaron a tener muy poca relevancia social y mayormente se encargaron de la actividad rutinaria; la imagen del juez se convirtió en la de un burócrata adverso a la innovación. El Estado por su parte invirtió muy poco en la administración de justicia, la cual tenía que arreglárselas con tecnología obsoleta, organización pobre, y jueces mal pagados y mal entrenados. La ineficiencia, la influencia ambulante e incluso la corrupción se hicieron comunes en todos los tribunales de Latinoamérica.

A nivel normativo, los códigos de procedimiento civil y penal que databan de mediados del siglo diecinueve y otra legislación anticuada aún cargan la administración de justicia en la mayor parte de Latinoamérica con un proceso basado en documentos que es costoso y toma mucho tiempo. Por ejemplo en Uruguay, el Código de Procedimientos Civiles recientemente derogado databa de 1879, el cual era una copia del Código Español de 1850 que contenía muchos elementos medievales (Marabotto, 1993). Además, los problemas institucionales/estructurales aún plagan la administración de justicia en todo Latinoamérica. Los expedientes atestados que resultaban de una cantidad insuficiente de jueces mal pagados para tratar la carga de casos y la falta de recursos adecuados, junto con los procedimientos civiles y penales dominados por procesos documentarios no orales tratados en el despacho de jueces, alienta la resolución de casos mediante personal no judicial, tales como actuarios, o secretarios (Correa, 1993: 8). No pocas veces un juez revisa apenas por encima un expediente producido por su secretario y firma los fallos con poco o ningún análisis. Esto es particularmente serio en procesos penales, planteando cuestionamientos de debido proceso. 
En la mayoría de países de Latinoamérica, el Poder Judicial es una empresa de servicio civil público que no obstante ha sido organizado en forma tradicional como un sistema cerrado. Si bien está externamente sujeto a diferentes grados de control político por parte del Poder Ejecutivo, las Cortes Supremas por lo general ejercen control con mano de hierro sobre la administración interna de las cortes, incluyendo selección del nivel de ingresos y promoción de los jueces de tribunales inferiores. Una vez que un miembro del poder judicial, un juez joven es asignado a un tribunal inferior en una de las provincias, subiendo en forma gradual la escalera de la carrera hacia puestos judiciales más altos y mejor pagados y condiciones de vida más tratables. Si persevera y no entra en conflictos con las cortes de apelación superiores y la Corte Suprema, podría ser nombrado para una Corte de Apelación o incluso para la Corte Suprema. Este sistema perpetúa un sistema de empleados públicos que recompensa la reverencia y las buenas conexiones. Pero es evidente cierto progreso. Un producto de los programas de reforma legal, nuevas escuelas judiciales en Chile, Uruguay y otros países parecen estar erosionando el sistema de empleados públicos. El mérito se ha convertido en un criterio relevante para la selección, dándose preferencia a los candidatos que han concluido exitosamente el curso completo o los seminarios especiales en los nuevos colegios judiciales (CEJU, 1993).

Una combinación de fuerzas sociales, estructurales y culturales han hecho que sea difícil lograr un acceso efectivo a la justicia, particularmente para los sectores con menos ventajas de la sociedad. En Chile, por ejemplo, un estudio llevado a cabo en 1993 (Correa y Barros, 1993: 73-89) indicó que sólo $32 \%$ de aquellos que habían sufrido algún acto criminal (de lejos su "problema legal» más común) llamaron o fueron a la policía para presentar su denuncia, y de éstos, un total de $57 \%$ no recibieron respuesta alguna. Al final, de las cien víctimas de un acto criminal, sólo 1.5 obtuvo un proceso penal completo contra un demandado. Entonces, es asombroso que $71 \%$ de los que denunciaron un acto criminal concluyeron que recurrir a la justicia había sido una pérdida de tiempo, y que un $68 \%$ de los que sufrieron un acto criminal nunca se molestaron ni si quiera en presentar su denuncia a alguna autoridad. Para ellos, por lo menos la «justicia» era inalcanzable. Los juicios civiles ya no son accesibles. Como en la mayoría de países, por ejemplo, litigar en Argentina no resulta económico; además de los 
honorarios del abogado, desde fines de 1993, las partes que inician una acción civil o comercial deben hacer un depósito en garantía en la corte que asciende al 3\% del monto demandado, recuperable sólo si el demandante gana el caso (Prado, 1993).

Finalmente, la cultura legal, es decir, las percepciones prevalecientes de lo que representa el sistema legal junto con las prácticas y usos reales que están engranados con la profesión, pueden afectar de manera vital su acceso y efectividad. La mayoría de los latinoamericanos tienen opiniones muy negativas respecto a los procesos legales en general y la administración de la justicia en particular. En Argentina, por ejemplo, $61 \%$ de la muestra de una encuesta de Gallup de 1992 señaló un ineficiente sistema judicial como la causa más importante de la corrupción (citado en Moreno Ocampo, 1993: 199.) De manera similar, una encuesta de 1993 en áreas de menores ingresos de las tres principales ciudades de Chile revelaron que $83 \%$ de la muestra tenía percepciones muy negativas de la administración del sistema de justicia en general, considerándolo ineficiente, discriminatorio, arbitrario, lento y corrupto (Correa y Barros, 1993: 23-26).

A pesar de la insuficiencia de los estudios empíricos de la cultura legal del sistema judicial de América Latina y otros actores legales, expertos en derecho y otras áreas han estado por mucho tiempo preocupados por las raíces históricas y sociales de la cultura legal de América Latina. Maier (1993: 29-31), por ejemplo, apunta a la herencia cultural del período colonial. Al momento de la conquista, la corona española estuvo comprometida en un proceso de formación de naciones y de poder centralizador en una absoluta monarquía. Como lo hizo con otras instituciones, el régimen colonial español impuso en sus colonias un sistema judicial basado en su propio modelo político; a saber, un sistema jerárquico centralizado con mecanismos de control altamente desarrollados sobre las cortes de instancias menores (Saez, 1998: 1280). El sistema judicial fue estructurado como una organización burocrática, en la que el poder era delegado verticalmente a los funcionarios de niveles inferiores, y en los que cada juez y cualquier otro personal judicial era un funcionario al servicio del Estado, no de la persona. El sistema judicial por lo tanto no era concebido como una institución para resolver conflictos de la población en su totalidad, sino como un componente de la administración del poder del Estado; es decir, como un instrumento de control social. 
Esta tradición legal sólo se vio parcialmente afectada por el proceso de independencia en América Latina (Maier, 1993: 32-35). Las articulaciones retóricas de la ideología liberal, sin perjuicio de la independencia y del cambio de una monarquía absoluta por las formas republicanas de gobierno no daba como resultado un nuevo orden social sino más bien un cambio de una elite ibérica por su contraparte local o criolla, que no quería en particular compartir el poder político con las masas empobrecidas. Si bien las reformas liberales de la Europa del siglo XIX ampliaron la esfera de los derechos individuales, establecieron la separación de poderes y promovieron una mayor participación ciudadana en el proceso político, su impacto fue atenuado en el contexto social tan diferente de América latina.

A pesar de los recientes esfuerzos de reforma, la administración de justicia en América Latina en gran medida continúa basada en un modelo burocrático, como tal, se encuentra jerárquicamente organizada y conserva un proceso escrito que facilita el control interno de los procesos (y los funcionarios judiciales), pero limita de manera estricta la participación en el proceso por las partes afectadas. Este es un modelo que aún refleja la cultura legal/política no participativa patrimonial, centralizadora, heredada de la norma colonial española. Como Moreno Ocampo lo señala, «la ley en esta tradición es un medio para un ejercicio del poder del Estado con el fin de controlar sus asuntos» (1993: 200).

La profesión legal continúa en gran parte siguiendo la tradición «liberal» de la práctica individual, o en el caso de compañías de orientación internacional, más grandes y más "modernas", la de estar organizadas alrededor de familias, similares a las «dinastías legales». Pero la sofisticación e internacionalización de estos practicantes legales más modernos, muchos con grados de las más prestigiosas escuelas de Derecho en EE.UU., no comprende necesariamente la absorción de los derechos humanos o los valores democráticos. En gran medida, estos abogados «modernos» están dedicados a la práctica privada que cada vez más comprende la estructuración de operaciones comerciales con inversionistas locales o extranjeros de conformidad con criterios internacionalmente aceptados, pero con poca, si alguna, preocupación sobre temas que abarcan el rol de las leyes en la sociedad (Dezalay y Garth, 1998: 58-60). 
A pesar de que ciertamente no es la única causa, en gran medida, la persistencia de esta cultura jurídica puede estar vinculada al modelo tradicional de educación legal dominante en toda América Latina. Salvo notables excepciones, la formación de cinco a seis años y el entrenamiento recibido por los estudiantes de Derecho carece del amplio enriquecimiento del debate crítico y está más vinculada a la pedagogía tradicional basada en su mayoría en fuentes legales extranjeras, de estilo autoritario, enciclopédico y con énfasis en la memorización. Dada la base de "leyes naturales racionalistas" de los Códigos, conocer su contenido es conocer «la ley». Esta tesis es inculcada a lo largo de los años de la escuela de Derecho y reiterada en un saber legal con escasas relaciones con la realidad, formando un sistema dogmático de conocimiento y verdad que pocos han podido cuestionar o resistir (Dezalay y Garth, 1998: 32-33). El saber y la educación legal hoy en día, a pesar de las continuas críticas y algunas notables excepciones, continúa siendo, en gran medida, invariable.

Los aspectos prácticos e instrumentales del proceso legal se «aprenden» en gran medida a través de la experiencia laboral; respecto a los aspectos más «modernos» de la ley, esta oportunidad está generalmente limitada a aquellos con las conexiones apropiadas o que han tratado de asistir a escuelas de Derecho más elitistas. En cualquier caso, este aspecto de «cultura legal» prevaleciente no conduce en particular a un discurso o proceso democrático participativo, en un momento cuando las sociedades latinoamericanas están comprometidas en serios esfuerzos de «redemocratización» y modernización económica. En cierta medi$\mathrm{da}$, los sistemas e instituciones legales han perdido relevancia frente a las necesidades sociales y económicas de la región (Faria, 1993: 14, 25).

\section{Conclusiones}

Las percepciones de una interdependiente y compleja relación economía global/democratización con los sistemas legales, en general, y sus sectores de justicia, en particular, han llevado al Banco Mundial, a otros actores globales, así como reformistas nacionales, académicos y elites económicas y modernizadoras a solicitar cambios en la administración de justicia, que conducen a complejos procesos de reforma legal. 
Tal como se observó, un fundamento principal para el apoyo activo del Banco Mundial para los proyectos de reforma legal en América Latina es la premisa que los ambientes legales seguros y predecibles son necesarios para la inversión y un desarrollo orientado al mercado. Pero algunos cuidadosos estudiantes de sistemas legales de América Latina cuestionan esta premisa, argumentando en lugar de ello que la certeza de que los inversionistas buscan ha estado históricamente más relacionada con estructuras judiciales políticas antes que legales y judiciales. Con seguridad, los sistemas judiciales débiles e ineficientes, los expedientes acumulados y otras deficiencias similares son una realidad en todo América Latina. Pero los casos que comprenden a los pequeños deudores, delitos menores, crímenes comunes (opuestos a la corrupción o crímenes de altos funcionarios), entre otros problemas, son el tipo de casos más frecuentes que confrontan los sistemas judiciales en la región. Los grandes jugadores tienden a resolver sus disputas en otros escenarios, como los tribunales arbitrales internacionales o las agencias ejecutivas o administrativas (De la Barra, 1998).

Incluso cuando, como en Argentina, se adoptan innovaciones efectivas parcialmente en respuesta a inversionistas extranjeros que quieren garantías a través de instituciones legales, éstas tienden a estar limitadas a procesos de resolución de disputas privadas, como mediación o arbitraje, que funcionan «fuera pero alrededor de las instituciones públicas del Estado" (Dezalay y Garth, 1998: 95). Como resultado, llegan a la conclusión de que el proyecto de reforma legal del Banco Mundial en Argentina, iniciado en 1992, "[...] no ha dado resultados tangibles\} (1998: 89). Dado este contexto, quizás el Banco y otras agencias multilaterales deban reconsiderar su premisa que considera que el poder judicial es el actor institucional principal en producir la estabilidad asumida que será necesaria para el desarrollo de mercado.

¿Qué pasa con la presunta relación entre instituciones legales y democráticas en América Latina? Los reformistas de América Latina, profundamente influenciados por sus duras experiencias bajo los regímenes autoritarios, han llegado a considerar al sector de justicia efectivo como un factor clave para consolidar sus aún frágiles procesos de democratización. Tal como Correa lo anota (1986: 212-218), el único proyecto actualmente viable en términos sociales y políticos para América Latina es la democracia liberal, que a su vez implica un respeto por las normas legales. Incluso, estos traficantes de reformas no serían los 
primeros en reconocer que las cortes de América Latina en gran medida no llevan un legado como defensores de derechos humanos o instituciones democráticas. Tal como se argumentó anteriormente, no solamente se debe a una falta de recursos, entrenamiento técnico inadecuado y otras deficiencias institucionales. Más importante que eso son las culturas legales y judiciales que se han desarrollado a través de los siglos como un reflejo de los procesos y estructuras sociales y políticos. Saez, muy perspicazmente, reconoce que la reforma de la estructura judicial oficial debe ir a la par de los cambios relevantes en las instituciones informales y los acuerdos de organización, pues éstas en gran medida reconocen un efecto controlador en el sistema formal (1998: 1319). «Incluso, una de las preguntas básicas que confrontan cualquier esfuerzo de reforma es cuánto cambio producen dentro del sector judicial, si el comportamiento fuera de los sectores permanece relativamente invariable». (Hammergren, 1998: 13). El mismo Banco Mundial en una declaración de política relativamente reciente sugiere que los programas de reforma judicial deben tratar las causas legales, políticas y económicas en la raíz de un sistema judicial ineficiente e inequitativo, pues de otra manera, "[...] habría una mínima probabilidad de éxito" (Lawyers Committee, 1996:6), citando a una fuente bancaria no especificada.

¿Cuáles son entonces las perspectivas de las reformas legales propuestas y actuales en América Latina?

Los recursos financieros disponibles de varios donantes extranjeros han influido, sin lugar a duda, en el proceso de reforma. No obstante, varios países iniciaron proyectos de reforma y han avanzado en su agenda antes de la llegada de los agentes globales o con mínima asistencia externa o interna. Estos países comprenden Brasil, Chile, Costa Rica y Uruguay, con diferentes grados de éxito (Hammergren, 1998. 23). Incluso, se pueden observar reevaluaciones y reformulaciones críticas de sus sistemas legales e importantes cambios en toda la región. La tradicional cultura legal, por ejemplo, está siendo objetada, y muchas escuelas de leyes han pasado a ser activas en sus movimientos de reforma legal, haciéndose más activas en sus publicaciones e investigaciones legales, críticas, orientadas a la política, e introduciendo lentamente reformas curriculares y clínicas en sus programas. Quizás, el experimento más notable, financiado por la Fundación Ford, es un programa clínico de interés público activo realizado entre Escuelas de Leyes en 
Argentina, Chile, y Perú, que periódicamente se reúnen para tratar sus experiencias y coordinar actividades (Gonzales Morales, 1997). Las innovaciones estructurales comprenden CEJU, la escuela de Derecho recientemente instituida en Uruguay, que se ha convertido en la principal fuente de candidatos para el sistema judicial y la oficina del procurador público, como parte de un proceso por liberar la tradicional influencia de la Corte Suprema sobre el ingreso en la carrera judicial. Más aún, los talleres CEJU están entrenando jueces en técnicas de ADR así como actualizándolos en otras innovaciones y desarrollos legales. En Argentina, el Ministerio de Justicia tiene un programa bien organizado de entrenamiento en mediación y difusión y ha introducido como un componente esencial en su clínica de ayuda legal en cuatro vecindarios de bajos ingresos. Otros países también han inaugurado academias judiciales y se encuentran en el proceso de reemplazar a los magistrados investigadores (inquisidores) con una oficina de procurador público independiente, introduciendo audiencias orales en sus procesos civiles y penales y mejorando de manera sustancial sus programas de defensoría pública y legal.

No obstante, si bien los juicios orales y otras reformas innovadoras pueden ampliamente mejorar la administración de justicia, éstos también requieren mejoras estructurales complementarias, como jueces y personal de apoyo mejor entrenado, espacio físico adecuado para permitir a los jueces realizar audiencias con la presencia de las partes opositoras, asesores e incluso público interesado, computarización de procesos judiciales y vínculos informáticos a datos legales esenciales, $\mathrm{y}$ mejoras en otros servicios públicos cuya colaboración oportuna es esencial para una eficiente administración de justicia, como la policía de investigaciones, otros departamentos que deben emitir informes oficiales o estadísticas, los registros públicos y similares. De esta manera, incluso si las reformas propuestas llevan a las metas deseadas, su implementación enfrenta dificultades que pueden ir más allá de las capacidades de entidades nacionales y sus aliados externos (Hammergren, 1998: 25 y ss.)

El régimen de la ley y una administración justa, accesible y factible de justicia pueden constituirse en los pilares para una democracia efectiva. Pero los efectos colaterales potencialmente adversos de los proyectos de reforma de ley no pueden ser ignorados; un puro enfoque de libre mercado, por ejemplo, llevará inevitablemente a una concentra- 
ción de recursos en unos cuantos privilegiados. De esta manera, si los pobres van a participar de manera más uniforme del crecimiento económico, deben contar con un acceso efectivo a la asignación de bienes y servicios, incluyendo justicia. De manera similar, si los indígenas por tanto tiempo descuidados pero recientemente confiados participan en la esperanza de los beneficios de las reformas y adquieren la fuerza de los ciudadanos, ni los actores nacionales ni los globales podrán ignorar la realidad del "pluralismo legal». Existen diversos sistemas legales operacionales en toda América latina; son parte del universo legal e ignorarlos no es más que una negación social (Guevara y Thorne, 1992). De manera similar, el reconocimiento y la atención se debe a las cada vez mayores demandas justificadas de los sectores municipales y provinciales para la mayor autonomía fiscal y política, que busca un extremo del sistema tradicional de la autoridad centralizada que prevalece sobre la mayoría de América Latina. Si bien la economía global está llevando a una ley y una revisión judicial supranacional, los movimientos indígenas y regionales están al mismo tiempo «localizando leyes y políticas, iniciando un proceso de redistribución de soberanías donde el estado pierde el poder en ambas direcciones» (Merryman, 1985: 158).

Al discutir los recientes programas de reforma legal financiados del Banco Mundial en Africa, McAuslan críticamente analiza las premisas y enfoques del Banco a un reforma legal, cuestionando si «[...] el desarrollo legal $[\ldots]$ puede lograr un buen gobierno y puede desarrollar la economía de mercado tanto en países en desarrollo como en países en transición [...]" (1997:25). Considerando este reto, ¿cuál debe ser la respuesta a las agencias globales y otros actores involucrados en la reforma legal? A riesgo de ser simplista, sugeriría mirar hacia atrás antes de dirigirse hacia el sur, y una vez que se dirija hacia el sur, mirar hacia el sur. Un punto de inicio lógico, sería revaluar cuidadosamente los programas de Derecho y desarrollo de los años sesenta y los setenta, también sobre las premisas de la centralidad de la ley para promover el desarrollo en los países menos desarrollados. Con seguridad, el monto ha cambiado desde entonces, no obstante, la falta de éxito total de Derecho y desarrollo despierta incógnitas y da lecciones relevantes a los actuales esfuerzos de reforma legal global. Incluso, uno se puede preguntar, si la "ley" no condujo al "desarrollo", entonces, ¿por qué lo haría ahora?. 
Para empezar, uno necesita mirar el informe germinal de 1974 del Comité de Asesoría para las Investigaciones sobre Derecho y Desarrollo del Centro Legal Internacional. Después de reconocer el centro defectuoso del movimiento de Derecho y desarrollo de los sesenta y setenta, este informe clamaba por una visión más realista del rol de la ley, enfatizando la necesidad de ir más allá de las normas formales para determinar quién tiene acceso a los procesos legales y cómo se toman las decisiones efectivamente. El informe también enfatizó la necesidad de una investigación socio legal que va más allá de la premisa de que la ley desempeña un papel positivo sino que más bien reconoce que puede distorsionar o incluso ser un obstáculo para el desarrollo, al esconderse detrás de la fachada del cambio y la igualdad legal (McAuslan, 1997:26). Después de todo, «[...] raras veces los regímenes de la ley son verdaderamente significativos o interesantes en cuanto al sistema legal extranjero se refiere; son el clima social e intelectual, las estructuras institucionales, y la características de los procesos del sistema legal los que son instructivos" (Merryman et. al., 1994: p.viii). Si bien son casi trivialidades para los entendidos contemporáneos, estos conceptos con frecuencia son ignorados incluso como un servicio accesorio en los paquetes de ayuda a la reforma de ley actuales.

Se ha convertido en un lugar común enfatizar que los «esfuerzos reunidos para la reforma judicial no pueden tener éxito a menos que estén vinculados a medidas que tratan los factores estructurales, técnicos, políticos profundamente enraizados que inhiben el funcionamiento efectivo del poder judicial». La reforma no es neutral -producirá conflictos entre los "ganadores" y los "perdedores" (Pinheiro 1999:12). ¿Cómo se pueden tratar estos problemas? Entre los cursos de acción prácticos que los programas de reforma de ley futuros pueden adoptar está el de asegurar la total participación de los actores nacionales, incluyendo no sólo a los funcionarios del gobierno sino a los representantes de las partes de oposición y también a los representantes de grupos indígenas y organizaciones de base así como sociólogos experimentados, científicos políticos, eruditos en derecho, miembros del colegio, y otras personas o grupos relevantes. Esta participación es esencial para los estudios de reimplementación, así como para los estudios de seguimiento o evaluaciones continuas de los proyectos en cuestión. Más aún, también es necesario para mantener el principio de que la lección y la dirección de la reforma legal, una decisión política, descan- 
sa con cada país y no con la agencia que desembolsa préstamos y proporciona asesores externos (Faúndez, 1997: 3).

También hay una necesidad específica de promover vínculos más cercanos entre la comunidad de académicos y practicantes a través de talleres periódicos que comprendan a ambas comunidades. La colaboración de académicos y donantes y otras instituciones relevantes es necesaria para crear y organizar programas de entrenamiento con grado y materiales de enseñanza en aspectos de derecho y desarrollo. Más de un entendido ha señalando la necesidad de un enfoque renovado sobre estudios comparativos en la ley y los procesos de reforma en países desarrollados y en desarrollo, incluyendo el estudio de cómo las instituciones indígenas evolucionan y se adaptan a funciones modernas (McAuslan, 1997: 34', 43).

En cualquier caso, tanto los actores globales como nacionales involucrados en los procesos de reforma legal no deben descartar las lecciones tan frecuentemente ignoradas del pasado. Entre estas lecciones, sin ser la más pequeña, es que todas las reformas son políticas. La información global y la experiencia técnica en sí misma no es suficiente, el apoyo nacional de los componentes claves es crucial. Más aún, si bien se deben considerar las instituciones locales, éstas deben ser relevantes en los contextos locales. Finalmente, los actores de reforma deben estar preparados para embarcarse a viajes largos e impredecibles. No pueden haber puntos de llegada rápidos y fáciles para problemas sociales de tanto tiempo (Id., 37). 